\title{
Exposure to Intimate Partner Violence and Hypertension Outcomes among Young Women in South Africa
}

\author{
Nicole De Wet-Billings (iD) and Motlatso Godongwana (iD) \\ Demography and Population Studies, Schools of Social Sciences and Public Health, University of the Witwatersrand, \\ Johannesburg, South Africa
}

Correspondence should be addressed to Nicole De Wet-Billings; nicole.dewet-billings@wits.ac.za

Received 15 February 2021; Accepted 25 March 2021; Published 1 April 2021

Academic Editor: Tomohiro Katsuya

Copyright ( $\odot 2021$ Nicole De Wet-Billings and Motlatso Godongwana. This is an open access article distributed under the Creative Commons Attribution License, which permits unrestricted use, distribution, and reproduction in any medium, provided the original work is properly cited.

\begin{abstract}
Hypertension and intimate partner violence is affecting longevity and quality of life among women worldwide. In this study, intimate partner violence is identified as a risk factor for hypertension outcomes among young women in South Africa. Using a nationally representative sample of $216(\mathrm{~N})$ young women (15-34 years old) from the South African Demographic and Health Survey, this study uses cross-tabulations and logistic regression methods to identify the odds of hypertension outcomes. Results show that between 20 and $41 \%$ of 15-34-year-old women have hypertension. Further, $68 \%$ of women with hypertension experienced physical intimate partner violence. Finally, the odds of hypertension are increased if young women experience physical (OR: 4.07; CI: 1.04726-15.82438) or sexual (OR: 2.56; CI: 1.18198-5.55834) intimate partner violence. Efforts to reduce hypertension outcomes in the country should include intimate partner violence awareness and assistance.
\end{abstract}

\section{Introduction}

Intimate partner violence is a global pandemic affecting the lives of thousands of women. Intimate partner and genderbased violence in South Africa is currently higher than it is has ever been $[1,2]$. The most severe consequence of intimate partner violence is death. Globally, 30,000 women were intentionally killed by their intimate partners in 2018, a marked increase from the estimates 12,000 in 2012 [3]. In South Africa, $57.1 \%$ of female homicide deaths are by an intimate partner [4]. Recently, it has been reported that femicide is five times higher in South Africa than the global average [2]. Further, as many as $51 \%$ of South African women have experienced violence at the hands of an intimate partner in their lifetimes [2].

Intimate partner violence is also a known stressor for women, causing emotional and psychological trauma. Victims of intimate partner violence are reported to experience higher levels of depression, anxiety, and other mental health diseases [5-7]. In South Africa, a study showed that $30 \%$ of women who reported physical and emotional intimate partner abuse by their partners reported suicidal ideations [8]. Many global studies have similarly found a relationship between intimate partner violence and suicidal ideations and behaviours of victims [9-13]. Further intimate partner abuse increases the risk of sexually transmitted diseases (STDs) including HIV/ AIDS transmission, among women who experience physical and sexual assault $[14,15]$. Among young women (education grades 7-12) who experienced intimate partner violence in the USA, 7.1\% had reported having an STD [16]. Women who are abused by their partners also suffer from chronic diseases. A study of abused women in Spain found that $36.2 \%$ reported having a chronic disease (from a range of questions asked by the researchers) and 10.1\% had asthma [17]. In addition, physical injuries to victims of violence from their partners result in periods of hospitalisation and chronic pain conditions [18-21]. While this description of consequences includes various health outcomes, the list is not extensive and there is need to examine other health consequences associated with intimate partner violence. 
Hypertension is a form of cardiovascular disease that is more prevalent among females than males [22, 23]. In South Africa, an estimated $34.7 \%$ of females over the age of 15 years old are diagnosed with hypertension [24]. In the past, this disease was most prevalent among older females, but recent research in the country shows that $13.7 \%$ of $15-19$-year-olds and $12.5 \%$ of 20-24-year-olds have been diagnosed [24, 25]. This is most concerning since hypertension is a chronic disease which requires management through the use of medication, diet, and stress control, all of which have monetary implications which adolescents and young adults cannot afford [26].

Existing studies have identified tobacco and alcohol use, overweight and obesity, and diabetes, among others as risk factors for hypertension [27, 28]. Psychosocial factors are being investigated as contributing to cardiovascular diseases, such as hypertension. Recent studies have found that stress, depression, and social isolation contribute to cardiovascular disease risk [29-31]. A few studies have even examined the role of intimate partner violence on hypertension outcomes among women $[32,33]$. However, these studies were done on countries with lower intimate partner violence prevalence than South Africa. Also, from the above, hypertension prevalence among women in South Africa is also high and increasing among young women. South Africa was selected as a country of analysis because of the high burden of intimate partner violence (62\%) and hypertension among women (26.1\%). This makes South Africa the ideal study site to examine the relationship between intimate partner violence and hypertension outcomes. Further, empirical evidence is needed from less-developed countries to inform health policies and programmes and update current knowledge on the potential risk factors for cardiovascular diseases, such as hypertension.

\section{Materials and Methods}

2.1. Data. This study utilized secondary data from the 2016 South African Demographic and Health Survey (DHS). South Africa was selected as a country of analysis because of the high burden of intimate partner violence (62\%) and hypertension among women $(26.1 \%)$. Permission to use the data was obtained from the DHS program. The data include variables on intimidate partner violence such as experiences of physical, emotional, and sexual violence as well as information on hypertension diagnosis. Information on the demographic, socioeconomic, and HIV status is also included. The DHS program collects data at an individual and household level. To obtain all of the variables of interest, the individual female data file, the household data file, and the HIV biomarker data were all merged into a single file [34].

\subsection{Inclusion Criteria and Sample Size. A total of 3,514} women (15-49 years) were interviewed in the domestic violence (DV) module of the DHS survey. Due to literature showing an increase in hypertension among young women and the need to prevent chronic illness into later adulthood, only females aged 15-34 years' old who participated in the domestic violence DV module were included. A weighted sample of 687 women responded to questions on hypertension diagnosis. The study uses the DHS survey weights and details of the survey's procedure can be found in the South African DHS report [34]. Of these females, only 605 provided responses to questions on intimate partner violence (IPV). As such, a total of 605 females (15-34 years) were analysed. Of these, $35.7 \%(N=216)$ had hypertension. All missing observations were dropped from the analysis.

2.3. Study Variables. The outcome variable in this study is hypertension status. The question asked to respondents to obtain this variable was "Were you told that you had hypertension or blood pressure." This variable was treated as a binary variable as it consists of two categories coded as "no" (0) and "yes" (1).

The main predictor variable was exposure to intimate partner violence. To obtain this variable, the study used proxy measures for experiences of physical violence which included experience of being pushed, shook, or had something thrown at you (no (1) or yes (2)), kicked or dragged (no (1) or yes (2)), strangled or burnt (no (1) or yes (2)), and ever been threatened with a knife, gun, or other weapon (:no (1) or yes (2)). Other IPV variables that were used were experience of emotional violence (no (1) or yes (2)), experience of sexual violence (no (1) or yes (2)), experience of both physical and sexual violence (no (1) or yes (2)), experience of physical, emotional, and sexual violence (no (1) or yes (2)).

The demographic control variables that were included in this study were as follows: age grouped in 5-year intervals as 15-19; 20-24; 25-29; and 30-34 and race (Black (1); White/ Indian (2); Coloured (3). The White and Indian population groups were combined into one category because each individual category had very few weighted observations $(0.95$ and 1,04 , respectively). Other variables included were place of residence (urban (1); rural (2)), marital status (never married (1); married (2); separated/divorced/widow (3)) and whether the participant has ever had children (no (1) or yes (2)). The socioeconomic control variables that were used were highest education level obtained (no education (0); primary (1); secondary (2); higher (3)), wealth status (poor (1); middle (2); rich (3)), employment status (unemployed (1) or employed (2)) and whether the participant received a government/social grant (no (1) or yes (2)). Lastly, the HIV status (negative (1) or positive (2)) variable was also included in the study. While the variable selection may include covariates with no direct relationship to hypertension, these variables serve to create a profile of the demographic and socioeconomic characteristics of South African women. In doing so, these characteristics encapsulate important characteristics of the population who experience intimate partner violence and are at risk of hypertension and other noncommunicable diseases.

2.4. Data Analysis. The data were analysed using version 14.0 of the Stata software. This study begins with providing a description of the characteristics of women with 
hypertension. The study describes the respondent's experiences of IPV and the demographic and socioeconomic characteristics of women with hypertension. For the inferential statistical analysis, multivariate logistic regression was used to test and show the association between IPV and hypertension as well as the influence of each of the other predictor variables on hypertension diagnosis. The results from this analysis are reported using odds ratios and confidence intervals. The level of significance is set at 0.05 .

\section{Results}

From figure 1, the prevalence of hypertension was highest among older females as compared to younger females. About $41.8 \%$ and $39.9 \%$ of females aged $25-29$ and $30-34$ years have hypertension, respectively.

Figure 2 shows that $68.84 \%$ of the women who are hypertensive have experienced physical violence (PhysViol Yes) from their partners. Also, 37.39\% of hypertensive women have experienced emotional violence (EmoViol Yes) and $57.64 \%$ experienced sexual violence (SexViol Yes).

In terms of the demographic characteristics (Table 1), the levels of hypertension diagnosis were higher among coloured South Africans (46.4\%), females that resided on rural areas $(37.9 \%)$, and females who reported to have at least one child $(40.3 \%)$. About the socioeconomic characteristics, hypertension was prevalent among females who were married as compared to those that have never married or were separated. For example, almost $40 \%$ of females aged 15-34 years who were married were hypertensive. Females with no education $(42.6 \%)$ and with a poor wealth status (38.6\%) had higher levels of hypertension, respectively. Only about $40 \%$ of females who were employed had hypertension. However, the level of hypertension was higher among females who received a social grant compared to those that did not. Lastly, hypertension was not as prevalent among HIV positive females in this study. Only about $30.8 \%$ of females living with HIV were diagnosed with hypertension which is less than the percentage (36.8) of HIV negative females that had hypertension in this study. Only about $37.7 \%$ of females who experienced a combination of physical, sexual, and emotional violence had hypertension.

In the unadjusted logistic regression model (Table 2), physical violence was significantly associated with hypertension diagnosis. For example, females who had experienced some form of physical violence were $4.07(P<0.05)$ times more likely to be diagnosed with hypertension compared to those that have never experienced any form of violence [CI: 1.04726-15.82438]. The odds of hypertension were significantly higher among females who experienced sexual violence compared to those that have not [OR: 2.56; CI: 1.18198-5.55834].

Concerning the respondent's demographic characteristics, the odds of hypertension were significantly higher among females aged 25-29 [OR: 2.8621; CI: 1.439-5.69562] and 30-34 [OR: 2.64; CI: 1.32358-5.28812], respectively. A significant association was found between children ever born and hypertension status. The odds of hypertension diagnosis were 2.55 times $(P<0.05)$ among females who reported to have at least one child as compared to those that have no children [1.64351-3.98327]. Additionally, receipt of social grant was a significant predictor of hypertension status. For example, females who received a social grant were 3.33 $(P<0.05)$ times more likely to be diagnosed with hypertension [CI: 2.30984-4.82248].

\section{Discussion}

Hypertension is a chronic disease that compromises survival and quality of health outcomes. Females are disproportionately affected by hypertension globally and in South Africa $[22,35,36]$. While efforts, such as the South African Hypertension Society (https://www.hypertension.org.za/) which supports the dissemination of information and blood pressure testing throughout the country, are in place, intimate partner violence may affect women's ability to access care and treatment. This study was done to identify the relationship between intimate partner violence and hypertension outcomes among young women in South Africa. Results address pertinent risk factors for hypertension among young women in a country where intimate partner violence and gender-based violence have reached epidemic proportions.

This study finds an association between intimate partner violence and hypertension among young women in South Africa. Other studies have similarly found a relationship between gender-based and intimate partner violence and chronic health conditions, including hypertension [17, 32, 33, 37]. A confounding factor may be the stress caused by intimate partner violence that is also a contributor to hypertension [33,37]. Moreover, victims of intimate partner violence are known to also have less control over their finances, little or no decision-making authority within households, and as a consequence are unable to seek medical healthcare [38-40]. Under these circumstances, it is difficult to prevent or get treatment for a range of medical conditions, including hypertension. It is recommended that young women at risk of hypertension manage their diet, avoid stress, and seek medical attention as soon as possible [41]. However, with experiences of physical, sexual, and emotional violence from partners, these young women might not prioritise prevention or treatment measures or may be denied support from their abusive partners.

Hypertension also increases with age among women in South Africa. Age is a known risk factor for hypertension outcomes [42], but this study shows a significant proportion of youth who are at risk of the disease. Studies have identified that diet, alcohol in-take, sedentary lifestyles, and pregnancy are risk factors for hypertension in young women [27, 43]. In this study, $76 \%$ of respondents had ever given birth. Results here also show that having ever given birth is associated with increased risk of hypertension. Young mothers in South Africa also have high rates of intimate partner violence $[44,45]$. One study of women who gave birth at a Durban 


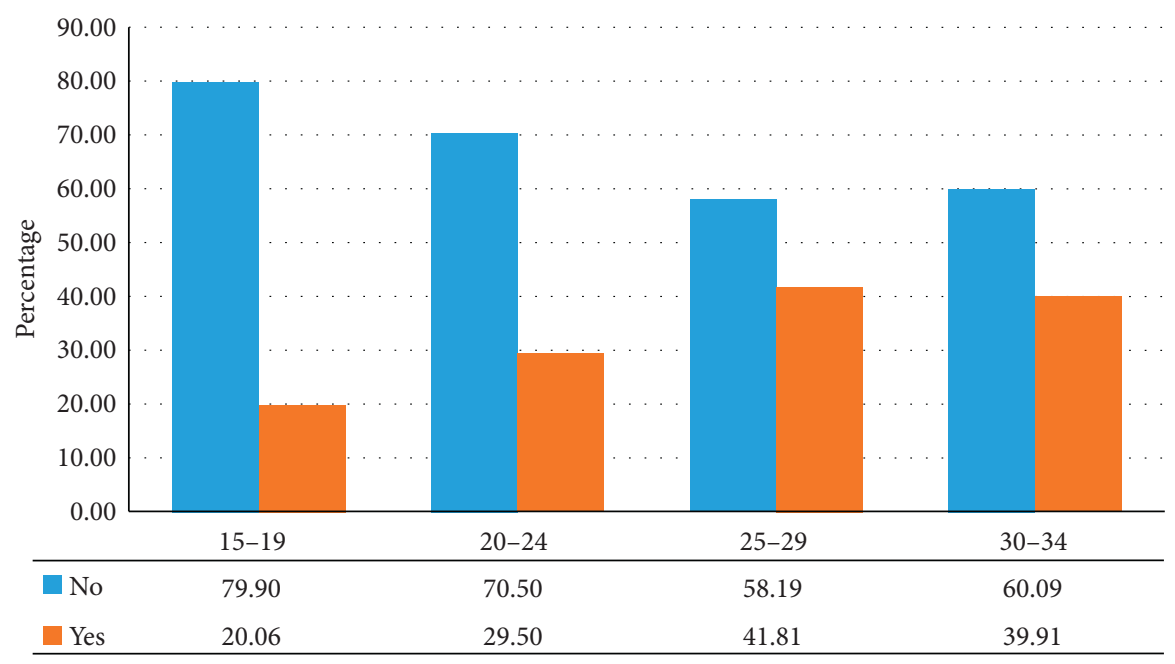

Hypertension status $(N=605)$

Figure 1: Percentage distribution of hypertension status (yes/no) by age group of the respondents, South Africa, 2016.

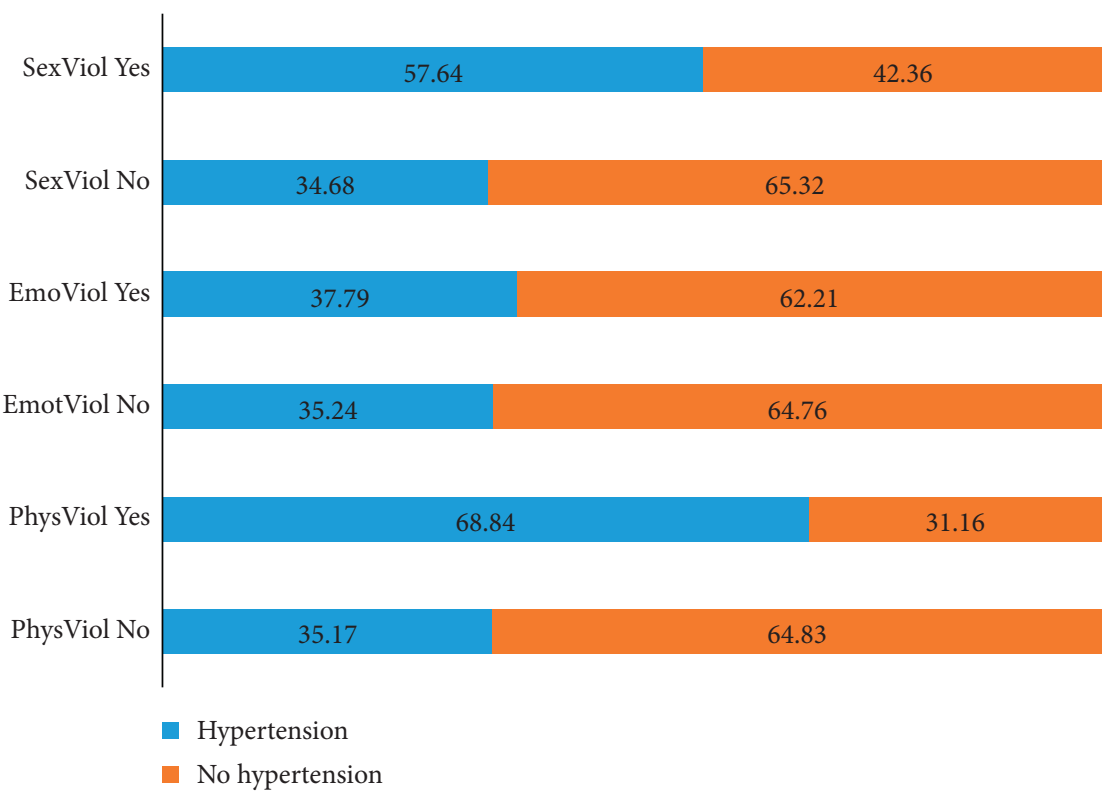

Figure 2: Percentage distribution of hypertension females (15-34 years old) by experiences of intimate partner violence, South Africa, 2016.

hospital found that nearly a quarter of women experienced intimate partner violence in the first nine months postpartum [44]. The stress of experiencing abuse postpartum could exacerbate the development of hypertension. Therefore, more efforts should be made to assist these young women.

This study uses secondary data, and therefore it cannot be determined if the intimate partner violence experiences predate the development of hypertension in young women in South Africa. Second, from the data, it is not possible to measure stress levels and other possible confounding factors that contribute to hypertension outcomes. Further, the study cannot determine if the hypertension status of these young women was pregnancy-related, as is the case of pre or postpartum hypertension. In addition, from the data, it is not possible to determine if the ways in which young women who experience intimate partner violence and have hypertension are managing their chronic illness. This would have offered insight into whether their abuse is in fact a hindrance to the care they receive for hypertension. Finally, the study is 
TABLe 1: Frequency and percentage distribution of respondents' characteristics by hypertension status, South Africa, 2016.

\begin{tabular}{|c|c|c|c|c|c|}
\hline \multirow{2}{*}{ Respondent characteristics } & \multirow{2}{*}{$\begin{array}{c}\text { Total } \\
\mathrm{N}\end{array}$} & \multicolumn{2}{|c|}{ Hypertension } & \multicolumn{2}{|c|}{ No hypertension } \\
\hline & & $\mathrm{N}$ & $\%$ & $\mathrm{~N}$ & $\%$ \\
\hline Total & 605 & 216 & 35.70 & 389 & 64.30 \\
\hline \multicolumn{6}{|l|}{ Race } \\
\hline Black & 552 & 195 & 35.28 & 357 & 64.72 \\
\hline White/Indian & 12 & 2 & 18.85 & 10 & 81.15 \\
\hline Coloured & 42 & 19 & 46.43 & 22 & 53.57 \\
\hline \multicolumn{6}{|l|}{ Place of residence } \\
\hline Urban & 421 & 146 & 34.74 & 275 & 65.26 \\
\hline Rural & 184 & 70 & 37.97 & 114 & 62.03 \\
\hline \multicolumn{6}{|l|}{ Children ever born } \\
\hline No & 144 & 30 & 20.91 & 114 & 79.09 \\
\hline Yes & 461 & 186 & 40.35 & 275 & 59.65 \\
\hline \multicolumn{6}{|l|}{ Marital status } \\
\hline Never married & 391 & 135 & 34.65 & 255 & 65.35 \\
\hline Married & 196 & 78 & 39.77 & 118 & 60.23 \\
\hline Separated & 18 & 3 & 15.35 & 16 & 84.65 \\
\hline \multicolumn{6}{|l|}{ Education level } \\
\hline No education & 5 & 2 & 42.66 & 3 & 57.34 \\
\hline Primary & 41 & 10 & 25.08 & 30 & 74.92 \\
\hline Secondary & 504 & 187 & 37.02 & 318 & 62.98 \\
\hline Higher & 55 & 17 & 30.97 & 38 & 69.03 \\
\hline \multicolumn{6}{|l|}{ Wealth status } \\
\hline Poor & 246 & 95 & 38.61 & 151 & 61.39 \\
\hline Middle & 159 & 59 & 37.09 & 100 & 62.91 \\
\hline Rich & 200 & 62 & 31.07 & 138 & 68.93 \\
\hline \multicolumn{6}{|l|}{ Employment status } \\
\hline Unemployed & 418 & 141 & 33.83 & 276 & 66.17 \\
\hline Employed & 188 & 75 & 39.94 & 113 & 60.06 \\
\hline \multicolumn{6}{|l|}{ Social grant status } \\
\hline No & 434 & 120 & 27.7 & 314 & 72.3 \\
\hline Yes & 171 & 96 & 56.12 & 75 & 43.88 \\
\hline \multicolumn{6}{|l|}{ HIV } \\
\hline Negative & 493 & 182 & 36.82 & 312 & 63.18 \\
\hline Positive & 112 & 35 & 30.87 & 77 & 69.13 \\
\hline \multicolumn{6}{|c|}{ Physical, sexual, and emotional violence } \\
\hline No & 490 & 173 & 35.24 & 318 & 64.76 \\
\hline Yes & 115 & 43 & 37.79 & 71 & 62.21 \\
\hline
\end{tabular}

based on self-reporting of hypertension status and not blood pressure measurements producing a reporting bias. However, in the absence of survey data which collects blood pressure and other vital measurements, self-reporting of disease diagnosis provides sufficient data, but a study that examines blood pressure measurements, in addition to selfreporting, would enhance our understanding in this area.
There are a few strengths of this study. First, the study uses a population-based sample where other studies have used smaller samples of women from clinics or enrolled in site-specific studies. Second, the study addresses two prevalent and growing issues of young women in South Africa, hypertension and intimate partner violence. Both are known to have detrimental consequences for women, 
TABLE 2: Unadjusted logistic regression of the odds of hypertension by characteristics of the respondents.

\begin{tabular}{|c|c|c|c|}
\hline $\begin{array}{l}\text { Respondent } \\
\text { characteristics }\end{array}$ & $\begin{array}{l}\text { Odds } \\
\text { ratio }\end{array}$ & $P$ value & $\begin{array}{c}\text { Confidence } \\
\text { interval }\end{array}$ \\
\hline \multicolumn{4}{|l|}{$I P V$} \\
\hline \multicolumn{4}{|l|}{ Physical violence } \\
\hline No & $\mathrm{RC}$ & & \\
\hline Yes & 4.07 & $0.043 *$ & $1.04726-15.82438$ \\
\hline \multicolumn{4}{|c|}{ Emotional violence } \\
\hline No & $\mathrm{RC}$ & & \\
\hline Yes & 1.11 & 0.608 & $0.73334-1.69947$ \\
\hline \multicolumn{4}{|l|}{ Sexual violence } \\
\hline No & $\mathrm{RC}$ & & \\
\hline Yes & 2.56 & $0.017 *$ & $1.18198-5.55834$ \\
\hline \multicolumn{4}{|c|}{ Physical, sexual, and emotional violence } \\
\hline No & RC & & \\
\hline Yes & 1.11 & 0.608 & $0.73334-1.69947$ \\
\hline \multicolumn{4}{|l|}{ Demographic } \\
\hline \multicolumn{4}{|l|}{ Age } \\
\hline $15-19$ & $\mathrm{RC}$ & & \\
\hline $20-24$ & 1.66 & 0.159 & $0.81858-3.39567$ \\
\hline $25-29$ & 2.86 & $0.003 *$ & $1.43921-5.69562$ \\
\hline $30-34$ & 2.64 & $0.006 *$ & $1.32358-5.28812$ \\
\hline \multicolumn{4}{|l|}{ Race } \\
\hline Black & $\mathrm{RC}$ & & \\
\hline White/Indian & 0.42 & 0.250 & $0.09974-1.82041$ \\
\hline Coloured & 1.58 & 0.152 & $0.84344-2.99638$ \\
\hline
\end{tabular}

\begin{tabular}{lrrr}
\hline $\begin{array}{l}\text { Place of residence } \\
\text { Urban }\end{array}$ & \multicolumn{1}{c}{ RC } & & \\
Rural & 1.14 & 0.447 & $0.80288-1.64594$ \\
\hline $\begin{array}{l}\text { Children ever born } \\
\text { No }\end{array}$ & RC & & \\
$\quad$ Yes & 2.55 & $0.000 *$ & $1.64351-3.98327$ \\
\hline
\end{tabular}

\begin{tabular}{lrrr}
\hline $\begin{array}{c}\text { Socioeconomic status } \\
\text { Marital status }\end{array}$ & & & \\
$\quad$ Never married & \multicolumn{1}{l}{ RC } & & \\
Married & 1.24 & 0.225 & $0.87388-1.77345$ \\
Separated & 0.34 & 0.101 & $0.09474-1.23430$ \\
\hline
\end{tabular}

Highest level of education obtained

\begin{tabular}{lrcc} 
No education & RC & & \\
Primary & 0.45 & 0.402 & $0.06941-2.91762$ \\
Secondary & 0.79 & 0.791 & $0.13888-4.4971$ \\
Higher & 0.60 & 0.586 & $0.09758-3.72841$ \\
\hline Wealth status & & & \\
Poor & RC & & \\
Middle & 0.93 & 0.759 & $0.62147-1.41480$ \\
Rich & 0.71 & 0.098 & $0.48317-1.06355$ \\
\hline
\end{tabular}

Employment status Unemployed RC

\begin{tabular}{lrrr} 
Employed & 1.30 & 0.147 & $0.91184-1.85675$ \\
\hline $\begin{array}{l}\text { Social grant status } \\
\text { No }\end{array}$ & \multicolumn{1}{c}{ RC } & & \\
Yes & 3.33 & $0.000 *$ & $2.30984-4.82248$ \\
\hline HIV status & & & \\
$\quad \begin{array}{l}\text { Negative } \\
\text { Positive }\end{array}$ & RC & & \\
\hline
\end{tabular}

* Significant $(P<0.05)$. and this study shows that there is a positive relationship between the two.

\section{Conclusions}

Intimate partner violence is associated with hypertension. Stress caused by violence perpetrated by a spouse or partner could be a confounding factor in the development of hypertension in young women. As a chronic illness which requires medication and specialised dietary requirements among others, hypertension is a costly disease. Young women in South Africa (and globally) are not all financially independent and cannot bear the costs of management and treatment alone. Therefore, all efforts to prevent the development of hypertension in young people should be pursued. For young women who experience intimate partner violence, this study shows that efforts to eradicate abuse will also aid in the reduction of hypertension. Identifying that intimate partner violence is a risk factor for hypertension assists local programmes and policies to develop more holistic approaches to care, prevention, and management strategies for young women.

Future research should focus on causality and determine if intimate partner violence does result in later hypertension outcomes. Further, a qualitative study which examines the coping mechanisms of intimate partner violence victims in relation to the management of hypertension will inform direct ways medical and social programmes can provide assistance to these women.

\section{Data Availability}

The data used in this study are from the South African Demographic and Health Survey (SADHS) and can be downloaded for analysis from https://dhsprogram.com/.

\section{Conflicts of Interest}

The authors declare that they have no conflicts of interest.

\section{Acknowledgments}

The authors thank the South African National Research Foundation (NRF) for providing funding to Nicole De WetBillings for this research.

\section{References}

[1] ISC, Gender-Based Violence And Femicide National Strategic Plan (GBVF-NSP), Department of Women, Youth and Persons with Disabilities (DWYPD), Pretoria, South Africa, 2020.

[2] Statistics South Africa, "Crimes against women in South Africa, an analysis of the phenomenon of GBV and femicide," in Statistics South AfricaStatistics South Africa, Pretoria, South Africa, 2020, https://www.parliament.gov.za/storage/ app/media/1_Stock/Events_Institutional/2020/womens_ charter_2020/docs/30-07-2020/A_Statistical_Overview_R_ Maluleke.pdf. 
[3] United Nations Office on Drugs and Crime, Global Study on Homicide: Gender-Related Killing of Women and Girls: UNODC, United Nations Office on Drugs and Crime, Austria, UK, 2018.

[4] N. Abrahams, R. J. Mathews, L. J. Martin, and C. Lombard, Every Eight Hours: Intimate Femicide in South Africa 10 Years Later! 2012, Medical Research Council, Cape Town, South Africa, 2012.

[5] P. Esie, T. L. Osypuk, L. M. Bates, and S. R. Bates, "Intimate partner violence and depression in rural Bangladesh: accounting for violence severity in a high prevalence setting," SSM - Population Health, vol. 7, Article ID 100368, 2019.

[6] H. A. Beydoun, M. A. Beydoun, J. S. Kaufman, B. Lo, and A. B. Zonderman, "Intimate partner violence against adult women and its association with major depressive disorder, depressive symptoms and postpartum depression: a systematic review and meta-analysis," Social Science and Medicine, vol. 75, no. 6, pp. 959-975, 2012.

[7] E. Ogbe, S. Harmon, R. Van den Bergh, and D. Olivier, "A systematic review of intimate partner violence interventions focused on improving social support and/mental health outcomes of survivors," PLoS One, vol. 15, no. 6, Article ID e0235177, 2020.

[8] A. Gibbs, K. Dunkle, and R. Jewkes, "Emotional and economic intimate partner violence as key drivers of depression and suicidal ideation: a cross-sectional study among young women in informal settlements in South Africa," PloS One, vol. 13, no. 4, Article ID e0194885, 2018.

[9] C. Wolford-Clevenger and P. N. Smith, "The conditional indirect effects of suicide attempt history and psychiatric symptoms on the association between intimate partner violence and suicide ideation," Personality and Individual Differences, vol. 106, pp. 46-51, 2017.

[10] W. Wu, Ye Zhang, G. Lloyd, F. Yan, H. Wang, and X. Li, “The mediating role of coping style: associations between intimate partner violence and suicide risks among Chinese Wives of Men who have Sex with Men," Journal of Interpersonal Violence, Article ID 0886260518814264, 2018.

[11] E. Brignone, A. E. Sorrentino, C. B. Roberts, and M. E. Dichter, "Suicidal ideation and behaviors among women veterans with recent exposure to intimate partner violence," General Hospital Psychiatry, vol. 55, pp. 60-64, 2018.

[12] J. L. Alhusen, N. Frohman, and G. Purcell, "Intimate partner violence and suicidal ideation in pregnant women," Archives of Women's Mental Health, vol. 18, no. 4, pp. 573-578, 2015.

[13] K. L. Chan, M. A. Straus, D. A. Brownridge, A. Tiwari, and W. C. Leung, "Prevalence of dating partner violence and suicidal ideation among male and female university students worldwide," Journal of Midwifery and Women's Health, vol. 53, no. 6, pp. 529-537, 2008.

[14] M. R. Decker, E. Miller, N. A. Kapur, J. Gupta, A. Raj, and J. G. Silverman, "Intimate partner violence and sexually transmitted disease symptoms in a national sample of married Bangladeshi women," International Journal of Gynecology and Obstetrics, vol. 100, no. 1, pp. 18-23, 2008.

[15] A. Gibbs, J. Jacobson, and A. K. Wilson, "A global comprehensive review of economic interventions to prevent intimate partner violence and HIV risk behaviours," Global Health Action, vol. 10, no. sup2, Article ID 1290427, 2017.

[16] K. L. Kerr Wilson, M. Javanbakht, M. Joelle, R. E. Weiss, P. Hsu, and P. M. Gorbach, "Intimate partner violence and sexually transmitted infections among young adult women," Sexually Transmitted Diseases, vol. 39, no. 5, 2012.
[17] I. Ruiz-Pérez, J. Plazaola-Castaño, and M. del Rio-Lozano, "Physical health consequences of intimate partner violence in Spanish women," The European Journal of Public Health, vol. 17, no. 5, pp. 437-443, 2007.

[18] M. A. Kernic, M. E. Wolf, and V. L. Holt, "Rates and relative risk of hospital admission among women in violent intimate partner relationships," American Journal of Public Health, vol. 90, no. 9, p. 1416, 2000.

[19] J. L. Fanslow and E. M. Robinson, "Physical injuries resulting from intimate partner violence and disclosure to healthcare providers: results from a New Zealand population-based study," Injury Prevention, vol. 17, no. 1, pp. 37-42, 2011.

[20] J. Wuest, M. Merritt-Gray, M. Ford-Gilboe, B. Lent, C. Varcoe, and J. C. Campbell, "Chronic pain in women survivors of intimate partner violence," The Journal of Pain, vol. 9, no. 11, pp. 1049-1057, 2008.

[21] E. Alhalal, M. Ford-Gilboe, C. Wong, and F. AlBuhairan, "Factors mediating the impacts of child abuse and intimate partner violence on chronic pain: a cross-sectional study," BMC Women's Health, vol. 18, no. 1, p. 160, 2018.

[22] J.-J. Song, Z. Ma, J. Wang, L.-X. Chen, and J.-C. Zhong, "Gender differences in hypertension," Journal of Cardiovascular Translational Research, vol. 13, no. 1, pp. 47-54, 2020.

[23] van Heerden, R. V. B. Alastair, S. A. Norris, K. Lisa, H. van Rooyen, and C. Celum, "High prevalence of HIV and non-communicable disease (NCD) risk factors in rural KwaZulu-Natal, South Africa," Journal of the International AIDS Society, vol. 20, no. 2, Article ID e25012, 2017.

[24] K. M. Berry, W.-A. Parker, J Zandile et al., "Quantifying unmet need for hypertension care in South Africa through a care cascade: evidence from the SANHANES, 2011-2012," BMJ Global Health, vol. 2, no. 3, Article ID e000348, 2017.

[25] R. Bhimma, E. Naicker, V. Gounden, L. Nandlal, C. Connolly, and S. Hariparshad, "Prevalence of primary hypertension and risk factors in grade XII learners in KwaZulu-natal, South Africa," International Journal of Hypertension, vol. 2018, Article ID 3848591, 9 pages, 2018.

[26] T. Fransman and D. Yu, "Multidimensional poverty in South Africa in 2001-16," Development Southern Africa, vol. 36, no. 1, pp. 50-79, 2019.

[27] S. Singh, R. Shankar, and G. P. Singh, "Prevalence and associated risk factors of hypertension: a cross-sectional study in urban Varanasi," International Journal of Hypertension, vol. 2017, Article ID 5491838, 10 pages, 2017.

[28] A. A. Leung, T. Bushnik, D. Hennessy, F. A. McAlister, and D. G. Manuel, "Risk factors for hypertension in Canada," Health Reports, vol. 30, no. 2, pp. 3-13, 2019.

[29] T. Dar, A. Radfar, S. Abohashem, and R. K. Pitman, A. Tawakol and M. T. Osborne, Psychosocial stress and cardiovascular disease," Current Treatment Options in Cardiovascular Medicine, vol. 21, no. 5, p. 23, 2019.

[30] E. J. Brunner, "Social factors and cardiovascular morbidity," Neuroscience and Biobehavioral Reviews, vol. 74, pp. 260-268, 2017.

[31] T. Tillmann, H. Pikhart, A. Peasey et al., "Psychosocial and socioeconomic determinants of cardiovascular mortality in Eastern Europe: a multicentre prospective cohort study," PLoS Medicine, vol. 14, no. 12, Article ID e1002459, 2017.

[32] S. M. Mason, R. J. Wright, E. N. Hibert, D. Spiegelman, J. P. Forman, and J. W. Rich-Edwards, "Intimate partner violence and incidence of hypertension in women," Annals of Epidemiology, vol. 22, no. 8, pp. 562-567, 2012.

[33] C. J. Clark, S. A. Everson-Rose, A. Alonso et al., "Effect of partner violence in adolescence and young adulthood on 
blood pressure and incident hypertension," PloS One, vol. 9, no. 3, Article ID e92204, 2014.

[34] National Department of Health, Statistics South Africa, South African Medical Research Council, and ICF, South Africa Demographic and Health Survey 2016, National Department of Health , Statistics South Africa, South African Medical Research Council and ICF, South Africa, 2019.

[35] E. E. Gillis and J. C. Sullivan, "Sex differences in hypertension," Hypertension, vol. 68, no. 6, pp. 1322-1327, 2016.

[36] T. V. Jardim, S. Reiger, S. Abrahams-Gessel et al., "Hypertension management in a population of older adults in rural South Africa," Journal of Hypertension, vol. 35, no. 6, p. 1283, 2017.

[37] J. C. Campbell, "Health consequences of intimate partner violence," The Lancet, vol. 359, no. 9314, pp. 1331-1336, 2002.

[38] S. Zegenhagen, M. Ranganathan, and A. M. Buller, "Household decision-making and its association with intimate partner violence: examining differences in men's and women's perceptions in Uganda," SSM - Population Health, vol. 8, Article ID 100442, 2019.

[39] A. L. McLeod, D. G. Hays, and C. Chang, "Female intimate partner violence survivors' experiences with accessing resources," Journal of Counseling \& Development, vol. 88, no. 3, pp. 303-310, 2010.

[40] N. Sharp-Jeffs, "A review of research and policy on financial abuse within intimate partner relationships," 2015, http:// repository.londonmet.ac.uk/1482/1/Review-of-Researchand-Policy-on-Financial-Abuse.pdf.

[41] Y. K. Seedat and B. L. Rayner, "South African hypertension guideline 2011," SAMJ: South African Medical Journal, vol. 102, no. 1, pp. 60-83, 2012.

[42] S. E. Kjeldsen, "Hypertension and cardiovascular risk: general aspects," Pharmacological Research, vol. 129, pp. 95-99, 2018.

[43] B. Sibai, "Chronic hypertension in pregnancy," Obstetrics and Gynecology, vol. 100, no. 2, pp. 369-377, 2002.

[44] A. K. Groves, D. Moodley, L. McNaughton-Reyes, S. L. Martin, V. Foshee, and S. Maman, "Prevalence, rates and correlates of intimate partner violence among South African women during pregnancy and the postpartum period," Maternal and Child Health Journal, vol. 19, no. 3, pp. 487-495, 2015.

[45] E. C. Davis, M. J. Rotheram-Borus, T. W. Weichle, R. Rezai, and M. Tomlinson, "Patterns of alcohol abuse, depression, and intimate partner violence among township mothers in South Africa over 5 years," AIDS and Behavior, vol. 21, no. 2, pp. 174-182, 2017. 